\title{
LA REPÚBLICA CHILENA ANTE LA CUESTIÓN INDÍGENA $(1810-1830)^{*}$
}

\author{
POR \\ LUCRECIA RAQUEL ENRÍQUEZ \\ Académica del Instituto de Historia de la Pontificia Universidad Católica de Chile
}

\begin{abstract}
RESUMEN
Este artículo analiza la forma en que los patriotas consideraron y resolvieron la inclusión de los indios en el nuevo sistema político a construir en Chile a partir de 1810 en base a tres aspectos interrelacionados. En primer lugar la desarticulación de los pueblos de indios, la inclusión social como ciudadanos iguales en una nueva sociedad no dividida en base a castas. En segundo lugar el proceso de identificación de los criollos chilenos con los mapuche-araucanos, a través de la apropiación del mito de Arauco. Y, en tercer lugar, la nueva definición del mito en clave republicana una vez que los araucanos apoyaron la causa realista.
\end{abstract}

PALABRAS ClAVE: mapuche-araucano, república, independencia, Chile, mito de Arauco.

\section{THE CHILEAN REPUBLIC ON THE CUESTION INDIGENA (1810-1830)}

\begin{abstract}
This article analyses the way in which patriots considered and decided the question about the inclusion of Indians (o native aborigines) to the new political system to be implemented in Chile from 1810. The problem will be worked out considering three interconnected aspects. Firstly, the dislocation of the Indian villages, the social inclusion considering them as citizens in a new society, not divided into castes. Secondly, the process of identification of Chilean creoles
\end{abstract}

\footnotetext{
* Este artículo forma parte del Proyecto Fondecyt $\mathrm{N}^{\circ}$, República y religión en Chile (1810-1833).
} 
with 'Mapuches-Araucanos' through the appropriation of the 'Arauco myth'. And thirdly, the new definition of the myth in republican terms, once the Araucanos decided to support the royalist cause.

KEY WORDS: Mapuche-Araucano, republic, independence, Chile, Arauco myth.

Recibido/Received 15/01/2011

Aceptado/Accepted 15/05/2011

\section{INTRODUCCIÓN}

El proceso de independencia de América, la guerra contra la Monarquía, la instalación de las repúblicas, los debates sobre los principios de la soberanía popular, la libertad, la igualdad, el nacimiento de los mitos nacionales, marcaron un hito, un antes y un después en la manera de considerar al indio. El salvaje, el bárbaro, definido así por la ciencia ilustrada monárquica, ${ }^{1}$ se convirtió paulatinamente a partir de 1810 en uno de los sujetos receptores de los beneficios del sistema político libre e igualitario, tanto en América como en España. En efecto, las cortes liberales españolas incluyeron, a propuesta de los diputados americanos, la abolición del tributo, la mita, la servidumbre, el reparto de mercancías, todas aquellas instituciones que habían caracterizado la implantación del poder español en América, aunque los indios quedaron fuera, junto con los esclavos, el servicio doméstico y las mujeres, de la plenitud de los derechos ciudadanos y de voto, hasta que fuera posible otorgarles todos los derechos cívicos en un futuro no definido.

Muchos de estos temas no eran totalmente nuevos, como el de la abolición del reparto de mercancías, al que se trató de poner fin, aunque infructuosamente, con la institucionalización de las intendencias en 1786, favoreciendo que los indios entraran al mercado como productores y trabajadores asalariados. En palabras de Campillo y Cosío, los indios eran el gran tesoro de la Monarquía, ${ }^{2}$ a los que se les debía distribuir tierra para fomentar la agricultura y convertirlos en consumidores de manufacturas europeas.

En este contexto en Chile, para mejorar la recaudación fiscal, se impulsó el pago del tributo directamente y en dinero a la Real Hacienda, el fin de la encomienda en 1791 y del servicio personal, y el asentamiento de los indios en pueblos, aunque con pocos resultados efectivos. Sin embargo, estas medidas

\footnotetext{
${ }^{1}$ Pedro NavARro Floria, «Salvajes y bárbaros: la constitución de la vida de barbarie en la frontera sur Argentina y Chilena», Boletín de Historia y Geografía, 13 (1997) Universidad Católica Blas Cañas.

2 José Campillo y Cosío, Nuevo sistema de gobierno económico para la América, Madrid, Imprenta de Benito Cano, 1789, 55.

Hispania Sacra, LXIII

128, julio-diciembre 2011, 627-652, ISSN: 0018-215-X
} 
contribuyeron a disminuir las distancias sociales de los indios con los españoles. Esta tendencia adquirió una nueva dimensión a partir de 1810 a raíz de la identificación por parte de los patriotas con los mapuche-araucanos, modelo heroico de la resistencia a la opresión del español, capaces de vivir en una república, entendida como autogobierno. ${ }^{3}$ La tendencia no fue sólo chilena, también en otros lugares de América se produjo la apropiación por parte de los criollos de la historia del mundo indígena, y una asimilación de sus virtudes a los miembros de los nuevos estados independientes. ${ }^{4}$

Analizaremos en este artículo la manera en que se trató la cuestión indígena a partir de 1810 en Chile hasta fines de la década de 1820, cuando se estableció una paz que se creyó duradera entre los indios y la república. El tema, desde nuestro punto de vista, contiene tres elementos a considerar interrelacionados según se fueron construyendo históricamente.

El primero, la inclusión de los indios como ciudadanos iguales en el Chile autónomo dentro de la Monarquía (1810) y en el proyecto de nación chilena después de la independencia (1818). ${ }^{5}$ En segundo lugar, la asimilación de la guerra desatada a raíz de las expediciones militares enviadas desde el Perú entre 1813-1814 con la de Arauco, ${ }^{6}$ ambas contra el mismo enemigo, y la consecuente identificación de los chilenos con los araucanos, mito fundante de la nación chilena. ${ }^{7}$ Finalmente, el más estudiado, la posición mapuche-araucana ante el cambio político, la adhesión a la causa realista, la guerra a muerte y la relación con la república ${ }^{8}$.

Somos consientes de que este tema requiere una investigación nueva y en sí misma, no posible de abordar por nosotros en este artículo, en particular la relación cambiante que los diferentes grupos que componían a sostuvieron con los

\footnotetext{
${ }^{3}$ Abelardo LeVAGGI, «República de Indios y República de españoles en los reinos de Indias», Revista de estudios histórico-jurídicos, 23 (Valparaíso 2001) Valparaíso,

${ }^{4}$ Ver Hans Joachim KöNIG, «El indigenismo criollo. ¿Proyectos vital y político realizables, o instrumento político?», Historia mexicana, XLVI/4 (1996).

${ }_{5}^{5}$ Jorge PINTO, La formación del Estado y la nación, y el pueblo mapuche. De la inclusión a la exclusión, Santiago, Dibam, Centro de investigación Diego Barros Arana, 2003, 67

6 José BengOA, Historia del pueblo mapuche, siglo XIX y XX, Santiago, LOM Ediciones, 2000; José Luis MartínEZ, Viviana GALLARDo «Construyendo identidades desde el poder: los indios en los discursos republicanos de inicios del siglo XIX», Colonización, resistencia y mestizaje en las Américas (siglos XVI-XX), Guillaume Boccara (ed.) Quito-Lima, Ed. Abya Yala, IFEA., 2002, 35; Eduardo CAVIERES, «Visiones y Revisiones de las Independencias Americanas: Los indios y las independencias», Stvdia Histórica. Historia Contemporánea, 27(2009) 75-98; Fernando CASANUEVA, «Indios malos en tierras buenas: visión y concepción del mapuche según las elites chilenas (siglo XIX)», Colonización, resistencia y mestizaje en las Américas (siglos XVI-XX), en Guillaume BocCARA (ed.) Quito-Lima, Ed. Abya Yala, IFEA., 2002, 291-327.

${ }^{7}$ Mario GóngORA, Ensayo histórico sobre la noción de Estado en Chile en los siglos XIX y XX, Santiago, Ediciones La Ciudad, 1981, 7 y 8

8 Tomás Guevara, Historia de la civilización de la Araucanía, Santiago, tomo 3, 1902.
} 
españoles y los patriotas en el período considerado. Trataremos el tema en base a la bibliografía y desde la óptica patriota republicana.

EL DESAFÍO PATRIOTA DE INCLUIR A LOS INDIOS EN EL NUEVO «SISTEMA DE GOBIERNO»

La historiografía chilena denominó la «Patria Vieja» al período que comienza con la formación de la Junta Gubernativa el 18 de septiembre de 1810 y concluye con la derrota patriota en la batalla de Rancagua (1 y 2 de octubre de 1814), que dio paso a la reconquista española. En estos cuatro años el proceso político avanzó desde una junta en nombre de Fernando VII a un planteamiento claramente independentista, que convirtió a Chile en un escenario de guerra a raíz del envío de tres expediciones militares de reconquista desde el Perú. Las diferentes juntas que gobernaron tomaron una posición política ante los indios en la frontera sur y los que habitaban en el territorio de la capitanía.

Analizaremos a continuación tres fuentes claves que ilustran de qué manera los patriotas consideraban su relación con los indios en esta primera etapa del cambio político. La primera, un Plan de Defensa del Reino, elaborado por encargo del cabildo de Santiago a una comisión compuesta por Juan Egaña, José Samaniego y el capitán de ingenieros Juan Mackenna en 1810,9 destinado a planificar la defensa contra los enemigos potenciales y reales. Entre los primeros se incluía a los araucanos a los que se los calificaba como indios sin subordinación, armas ni disciplina, aunque se los definía como los más valerosos de América. No se preveía en ningún caso la guerra con ellos, si bien era «opuesta a la felicidad como a la seguridad del reino la independencia de esos indios».10 Aconsejaban darles a conocer las ventajas del nuevo gobierno que buscaba «una estrecha unión con ellos», para lo cual proponían que se nombraran diputados con el fin de tratar el tema de la paz y del comercio. Sostenían además que no era conveniente reducirlos a pueblos porque aprenderían conocimientos militares y de todo tipo. Proponían introducir entre ellos haciendas y pueblos de españoles para que, por medio del casamiento, formaran con el tiempo una sola nación.

La segunda fuente a tener en cuenta fue el Plan de Gobierno, escrito por Juan Egaña, quien proponía que para financiar la educación industrial y científica debían venderse a censo los pueblos de indios a labradores honrados. Los indios debían recluirse en villas y desnaturalizarse, ${ }^{11}$ porque no convenía mantener las castas y en Chile no pagaban tributo formal. ${ }^{12}$ Egaña avanzaba así en

\footnotetext{
${ }_{9}$ Colección de Historiadores y Documentos relativos a la independencia de Chile, tomo 19, Santiago, Imprenta Cervantes, 1911.

10 Ibidem. 127.

${ }^{11}$ La desnaturalización implicaba el desarraigo de las comunidades indias.

12 Colección de Historiadores...103.
} 
el camino de la igualdad al proponer terminar con las categorizaciones sociales coloniales y, en definitiva, con la república de los indios.

La Junta Gubernativa, de hecho, dictó en febrero de 1811 un decreto sobre la igualdad de los indios y los españoles y su libertad de tributos. ${ }^{13}$

Avanzando en esta línea Juan Egaña elaboró un proyecto de constitución, y esta es la tercera de las fuentes que consideramos como fundamentales, comisionado por el Congreso que había comenzado sus sesiones en el mes de julio. En ella proponía declarar la igualdad de todos los hombres ante la ley en la república, la ciudadanía del indio y que cesaran las contribuciones y privilegios distintos entre indios y españoles, todo lo cual tendía al fin de la sociedad de castas. ${ }^{14}$

Continuó también la idea colonial de educar a una élite indígena. Una moción presentada por Manuel de Salas al gobierno el 20 de febrero de 1811 proponía unificar en uno solo los diferentes colegios que existían ${ }^{15}$. La propuesta abarcaba la Academia San Luis, la Universidad de San Felipe, el Seminario Conciliar, el Convictorio Carolino y el Colegio de Naturales de Chillán, donde se educaba a los hijos de los caciques araucanos ${ }^{16}$. La moción se convirtió en acuerdo del Congreso el 5 de octubre de 1811:

«Admitir a los indígenas en los colegios del estado en las mismas condiciones de igualdad que a los descendientes de españoles y que a este fin se destinen los dos mil pesos que anualmente se invierten en el Seminario de Naturales».17

La propuesta de Manuel de Salas se llevó a cabo en la fundación del Instituto Nacional el 10 de agosto 1813.

¿Qué pasaba en tanto en la frontera sur? Según Tomás Guevara los araucanos, en un primer momento, no dimensionaron «lo que significaba el movimiento de emancipación que se estaba gestando», 18 lo que tampoco les fue transmitido por los comisarios y los capitanes de amigos, que los españoles mantenían entre ellos.

El primer contacto con una de las facciones patriotas se produjo en 1811. La Junta de Gobierno formada el 18 de septiembre de 1810 dio paso a un Congre-

\footnotetext{
13 Ibidem 48.

${ }_{14}$ Sesiones de los Cuerpos Legislativos 1811 a 1845, tomo 1, Valentín Letelier, (comp.), Santiago, Imprenta Cervantes, 1887, p. 219.

${ }^{15}$ Cfr. José Manuel Frontaura, Historia del Convictorio Carolino, Santiago, Imprenta Nacional, 1889,30 .

${ }^{16}$ Karin Pereira Contardo, El Real Colegio de Naturales, Santiago de Chile, Publicaciones del Archivo Franciscano, 2002.

${ }_{17}$ Sesiones de los Cuerpos Legislativos... 118.

${ }^{18}$ Tomás Guevara, Historia de la civilización de la Araucanía, Santiago, tomo 3, 1902, 4.
} 
so compuesto por diputados elegidos de las diferentes ciudades. En él se manifestaron tres posiciones: los partidarios del antiguo régimen, que aspiraban a legitimar la autonomía política dentro de la Monarquía; los radicales, que postulaban la independencia; y los moderados, nacidos en el seno del cabildo de Santiago para equilibrar las otras dos posturas. Como estos últimos eran la mayoría del congreso cualquier eventual alianza con los más conservadores derivaba en un freno a las reformas políticas. Esto ocurrió cuando rechazaron una iniciativa de los radicales que impulsaban la formación de una junta ejecutiva, lo que derivó en la retirada del Congreso de los diputados radicales provenientes de Concepción, quienes formaron una Junta Provincial en dicha ciudad, y en el golpe de estado de los hermanos Carrera en Santiago, propiciado por la familia Larraín en septiembre de 1811. Así los radicales frenaron cualquier intento reaccionario avanzando hacia la implantación de reformas administrativas.

En este contexto la Junta Provincial de Concepción tomó la iniciativa de celebrar un parlamento con los araucanos, con el fin de atraer a su causa a los indígenas e incrementar el poder revolucionario en el sur. El parlamento se celebró el 24 de octubre y a él asistieron 13 caciques a los que se les comunicó el cambio de gobierno haciendo hincapié en las ventajas que esto les traería. Los araucanos aceptaron las nuevas autoridades y les ofrecieron indios de combate con la sola condición de que se los mantuviera durante el servicio. Aparentemente los indios se retiraron del parlamento sin una idea clara de lo que realmente significaba el cambio político. ${ }^{19}$

Para Barros Arana el objetivo de este parlamento era demostrar a los enemigos de la revolución el apoyo que la población indígena daba a la Junta Provincial. ${ }^{20}$ Según el cronista Talavera, monarquista, el objetivo llevar a cabo el cambio del sistema político y, para ello, enviar algunos indios al congreso como diputados. ${ }^{21}$

Si bien el partido radical tomó el poder a partir de agosto de 1811 tanto en Santiago como en Concepción, pronto se dividieron cuando José Miguel Carrera disolvió el congreso en diciembre de 1811, lo que derivó en un amago de conflicto armado entre las juntas de Santiago y de Concepción. Esta última formó un regimiento de indios auxiliares en la frontera. Pero como se decidió resolver pacíficamente el conflicto con los santiaguinos, el regimiento se dispersó. ${ }^{22}$ A partir de 1812 , desde la prensa y las proclamas gubernamentales,

\footnotetext{
${ }^{19}$ Cfr. Tomás Guevara...4.

${ }^{20}$ Diego Barros Arana, Historia general de Chile, tomo 8, Santiago, Rafael Jover editor, 1887, 448.

${ }^{21}$ Manuel Antonio Talavera, Revoluciones de Chile. Discurso histórico, diario imparcial, de los sucesos memorables acaecidos en Santiago de Chile por un vecino testigo ocular, 208.

22 Diego Barros Arana, Historia general de Chile, tomo VIII, Santiago, Rafael Jover editor, 1887,531 .
}

Hispania Sacra, LXIII

128, julio-diciembre 2011, 627-652, ISSN: 0018-215-X 
los radicales santiaguinos desarrollaron una nueva línea de acción tendiente a que los criollos se identificaran con los araucanos.

\section{EL MITO DE ARAUCO Y LA CAUSA PATRIOTA}

Se denomina guerra de Arauco al conflicto desatado a partir de 1550 a raíz de la conquista del territorio araucano por el imperio español. El origen de este mito es el poema épico de Alonso de Ercilla, La Araucana. Publicado en Madrid entre 1574 y 1589, evoca la etapa de la conquista del suelo chileno, la muerte de Pedro de Valdivia y de los caciques Lautaro y Caupolicán. Hacia mediados del siglo XVII comenzó una etapa menos belicosa entre mapuches e hispano-criollos, caracterizada por relaciones fronterizas y los famosos parlamentos en los que se negociaban los términos de la paz entre ambas partes, lo que significaba un status privilegiado de los mapuches en el imperio español. ${ }^{23}$ De hecho, la historiografía actual destaca que la relación entre los mapuche-araucanos y los hispano-criollos no se caracterizó por un enfrentamiento constante, sino que hubo etapas de paz, alianza y de intercambios.

Sin embargo, los elementos del mito de Arauco que afloraron a partir de 1810 fueron el guerrero y el amor a la libertad frente a un conquistador, íntimamente relacionados. Estos elementos contribuyeron a la imagen de Chile dentro del imperio como una «frontera de guerra» ${ }^{24}$ y de los araucanos como amantes de la libertad, resistentes a toda dominación, nunca vencidos. Esta imagen del araucano traspasó las fronteras chilenas tal como quedó de manifiesto en la Carta de Jamaica de Simón Bolívar:

«El reino de Chile está llamado por la naturaleza de su situación, por las costumbres inocentes y virtuosas de sus moradores, por el ejemplo de sus vecinos, los fieros republicanos del Arauco, a gozar de las bendiciones que derraman las justas y dulces leyes de una república. Si alguna permanece largo tiempo en América, me inclino a pensar que será la chilena. Jamás se ha extinguido allí el espíritu de libertad...». ${ }^{25}$.

La llegada de la imprenta en 1812 permitió la publicación del primer periódico con el prometedor título de La Aurora de Chile, redactado por fray Camilo Henríquez, fue fundamental en el camino constructor de la identificación de la causa patriota con la araucana, como quedó de manifiesto en el prospecto de fe-

\footnotetext{
${ }^{23}$ Cfr. Leonardo León, El parlamento de Tapihue, 1774, Santiago, Rehue, 1993, 7.

${ }^{24}$ Cfr. Mario Góngora, Ensayo histórico sobre la noción de Estado en Chile en los siglos XIX y XX, Ediciones La Ciudad, 1981, 7.

25 Simón Bolivar, Carta de Jamaica, Kingston, 6 de setiembre de 1815.
} 
brero de 1812, en el que se hacía hincapié en la causa común de indios y criollos a favor de los derechos de Fernando VII:

«Los fuertes habitantes de los cuatro butalmapus, los indios nos prometen una cooperación activa para repeler los insultos extranjeros, y sostener los derechos del desgraciado Fernando. Tal vez no dista el bienhadado momento de su conversión, civilización y cultura. Tal vez serán una de las glorias del Directorio sus progresos literarios, que hagan en el Instituto los felices ingenios de estos nuestros compatriotas, y hermanos, en quienes se conservan puros los rasgos de nuestro carácter nacional, y primitivo». ${ }^{26}$

Otro artículo de febrero de 1812 describía la fertilidad y abundancia del reino, la constatación de la reducción de la población aborigen desde la llegada de los españoles a causa de la guerra, las viruelas y las luchas internas o malocas, entre los mismos indios. Pero este panorama se había ido superando por la desaparición de las causas de devastación, la paz y la vacuna por lo que «es de esperar que la población siga entre nosotros los progresos de las luces, de la agricultura, de la industria y de la política», ${ }^{27}$ tal como había ocurrido en los Estados Unidos después de la independencia.

Continuaba con la misma reflexión en otro artículo titulado «Civilización de los indios», ${ }^{28}$ la que se había visto retrasada por el odio y recelo inicial contra los españoles, razón por la cual la paz había sido impracticable y había hecho fracasar la reunión en poblaciones como medio civilizador. De ahí que los araucanos, como nación libre e independiente, habían mantenido relaciones pacíficas y de amistad con el Rey de España por medio de sus representantes.

De esta manera Camilo Henríquez introducía a su público lector en estos dos elementos del carácter araucano a imitar, su sentido de independencia y de nación libre. Continuaba «El deseo de la libertad se acompaña siempre con el de la igualdad», destacando la importancia de que los indios sintieran que se los considera iguales a los españoles y que se iban a estrechar con ellos lazos sanguíneos. "Los indios están en condición de ser considerados una nación nueva, y por consiguiente, fácil y dispuesta para ser ilustrada», a través de sus hijos quienes, una vez educados, llevarían a su pueblo la religión, la moral, la industria, el comercio, la agricultura, dando un paso más hacia la formación de una sola familia y un solo gobierno de indios y españoles. A ello iba a contribuir el Instituto Nacional, lugar de educación de la juventud araucana.

Es posible observar, en el lenguaje que emplea Camilo Henríquez, la utilización del término español para referirse a todos los que no son indios, también a los criollos chilenos. Un artículo, aparecido en La Aurora, se refiere a este tema

\footnotetext{
26 Prospecto de La Aurora de Chile, febrero de 1812.

${ }^{27}$ Aurora de Chile, $\mathrm{N}^{\mathrm{o}} 3,27$ de febrero de 1812.

${ }^{28}$ Aurora de Chile, $\mathrm{N}^{\mathrm{o}} 12$, jueves 30 de abril de 1812 .
} 
al exponer las diferencias de los dos grandes grupos que habitaban América, españoles, europeos y americanos, por un lado, e indios, por otro. Los últimos vivían aún en su antigua barbarie, libres y sin leyes, ni luces, industria y religión. Los españoles americanos «descendemos de los conquistadores, pero no somos cómplices de la violencia que seguían sus armas», y poseían el mismo derecho que los indios a la tierra por haber nacido en ella.

Camilo Henríquez preguntaba entonces al lector si había habido una nación más calumniada y oprimida que los indios, de los que se dudó si eran seres racionales, por «sus bárbaros opresores» que se mancharon con horrendos crímenes. Citaba entonces a Aristóteles, quien caracterizó el amor a la libertad como propio de las almas fuertes:

«... ¿Quién no admira el ardor y la magnanimidad heroica con que combatieron por su libertad los indios chilenos?... Sólo el duro Araucano rehúsa las cadenas, y anteponiendo todos los males posibles a la pérdida de su libertad, y sin intimidarse por la inferioridad e imperfección de sus armas, resiste, combate, triunfa las veces, y cuando es vencido ni decae de ánimo ni pierde la esperanza de vencer». ${ }^{29}$

En el número del mes de octubre una poesía de Camilo Henríquez planteaba directamente la independencia de la progenie de Arauco gloriosa, ${ }^{30}$ en una total identificación entre araucanos y criollos, en unión a la promulgación de un Reglamento Constitucional provisorio que reconocía la autoridad de Fernando VII pero confirmaba la autonomía del gobierno chileno en la Monarquía. Se adoptaba también un escudo patrio que contenía una columna representando la libertad, flanqueada por dos indios, un hombre y una mujer. Apoyado en la columna un globo y arriba, en forma de cruz, una lanza y una pluma y encima escrito en latín «Después de las tinieblas la luz», por debajo de la columna otro lema también en latín «O por consejo o por espada».

Concluyeron en La Aurora estas reflexiones sobre los indios en aquel año de 1812 con la publicación de una carta enviada al editor por una sociedad de patriotas. Proponían que mientras se desarrollaba la lucha contra los opresores, se diera a conocer a los indios el nuevo sistema de igualdad. Remataba la carta diciendo: «Llamémonos todos indios desde ahora, para que nuestros hermanos conozcan el digno aprecio que hacemos de ellos». ${ }^{31}$

El número de febrero de 1813 de La Aurora daba a conocer la celebración de dos parlamentos con los indios. El primero en diciembre de 1812 en la plaza de Arauco entre los indios de la costa y el gobernador intendente de Concep-

\footnotetext{
${ }^{29}$ Aurora de Chile, $\mathrm{N}^{\mathrm{o}} 23$, jueves 16 de julio de 1812 .

${ }^{30}$ Aurora de Chile, $\mathrm{N}^{\circ} 23$, jueves 1 de octubre de 1812.

${ }^{31}$ Aurora de Chile, $N^{\circ} 23$, jueves 16 de julio de 1812 .
} 
ción, coronel Pedro José Benavente, con la presencia del obispo Diego Antonio Navarro Martín de Villodres y el prefecto de misiones. Los indios fueron informados del plan de defensa común y reconocieron el gobierno central. «Viva la unión, vivan los Araucanos, mueran los enemigos». El segundo parlamento se llevó a cabo en la plaza de Los Ángeles, en enero de 1813, con los indios de los llanos y de la costa. En él se renovó la alianza entre ambos butalmapus o regiones, y se reconoció el gobierno central de Chile. 32

La alianza con los indios tuvo su correlato en la condena a la conquista española, tal como se planteó en un artículo aparecido en La Aurora $^{33}$ en el que se analizaba la «Conspiración contra los pueblos» de fray Bartolomé de Las Casas, quien atribuía la muerte de doce millones a la sed de sangre de los españoles y su brutalidad, afirmando incluso que eran antropófagos. Remataba la nota una poesía: «... Cuantos males te esperan, dura España!/Vendrá día en que tantos atentados/Reciban su castigo.../Llego el plazo luctuoso, é inevitable/De tu fin, y tu ruina y cautiverio...» 34

La Aurora dejó de publicarse el 1 de abril de 1813 y fue reemplazado por $E l$ Monitor Araucano, periódico a través del cual la Junta de Gobierno daría a conocer sus decretos y obras. Continuaba como redactor fray Camilo Henríquez. Como bien señala Amunátegui, la razón del cambio de nombre obedeció a que ya había comenzado la guerra emprendida por España contra los insurgentes americanos, tal como quedó definido en la poesía del primer número: «Descendencia de Arauco gloriosa/Despertad el heredado ardor, /Que os esperan laureles triunfales/ $Y$ alto nombre en los campos de honor». ${ }^{35} \mathrm{Si}$ bien esta guerra era muy diferente a la que se había llevado a cabo contra los indios, como España argumentaba también el derecho de conquista, los revolucionarios hicieron suya la causa de los indios. ${ }^{36}$ Por otro lado, si un monitor es una persona que guía el aprendizaje de otra, el mensaje era que los chilenos, debían dejarse guiarse por el camino trazado por los araucanos hacia la libertad.

Las primeras noticias que se publicaron fueron las relativas a la llegada a Chile de la expedición española de reconquista desde el Perú, en marzo de 1813: «Concepción se prepara con todo el ardor araucano...».37 Una proclama afirmaba que Abascal había reducido a

\footnotetext{
${ }^{32}$ Aurora de Chile, $\mathrm{N}^{\mathrm{o}} 6$, jueves 11 de febrero de 1813 .

${ }_{33}$ Aurora de Chile, $\mathrm{N}^{\circ} 6$, jueves 25 de febrero de 1813 .

${ }^{34}$ Aurora de Chile, $\mathrm{N}^{\mathrm{o}} 6$, jueves 25 de febrero de 1813.

${ }^{35}$ El Monitor Araucano, tomo I, No 1 , martes 6 de abril de 1813.

36 Ver el prólogo de Colección de Historiadores y de Documentos relativos a la Independencia de Chile, tomo 26, Santiago, Imprenta Universidad, 1914.

${ }^{37} \mathrm{CHICH}$, tomo 24, Semanario republicano: busca impulsar la independencia, pp. 276-77.
} 
«... nuestros hermanos de Chiloé y Valdivia, para que sirvan a establecer su tiranía... Los VALIENTES ARAUCANOS pelean actualmente por defender el antemural de nuestros hogares; vamos a deberles nuestra gloria y nuestra felicidad. No los abandonemos y tengamos parte en sus heroicos esfuerzos. Carrera, Pinto, Vial». 38

\section{Otra proclama del 6 de abril arengaba a los}

«Patriotas y compañeros: nuestra libertad está escrita en el libro de los destinos, y este es sin duda el tiempo que el Eterno ha prefijado para que Chile recobre lo que en el siglo XVI se le usurpó con tanta inhumanidad como barbarie... No olvidéis que sois chilenos y que vuestro suelo siempre fue fatal a los tiranos. No sean los Rengos, los Tucapeles, los Caupolicanes, los Lautaros ni más intrépidos ni más celosos a la libertad Patria, que vosotros... Juan José Carrera».39

Los versos de fray Camilo Henríquez en El Monitor ilustraban aún más la identificación con los araucanos:

«Quien la libertad amaljamás vencido fue...»40 «Donde son insultados,/nuestros caros derechos,/los Araucanos pechos harán sentir su ardor». ${ }^{41}$ «Despertad la gloria/ del araucano nombre...» ${ }^{42}$ «Habéis visto la fuerza de la Patrial.../ Recordar a la América y al mundo/ Los nobles sentimientos, las hazañas/Y la gloria inmortal del claro Arauco/Después de tres centurias de silencio/Aman la libertad y los anima/las almas fuertes de los climas fríos./En sus pechos aún arde el fuego antiguolel amor al Estado y a sus leyes $/ Y$ el odio inextinguible a los tiranos...»43

Una nueva proclama del mes de agosto firmada por la Junta compuesta por Carrera, Portales y Vial, acentuaba aún más la identificación criollos-araucanos:

«Habitantes del estado de Arauco: nuestra libertad está escrita en el libro de los destinos, no lo dudéis. El Árbitro Supremo ha extendido su omnipotente mano sobre nosotros, ya solo resuena en todos los ángulos de Chile el dulce eco de la unión. Los Manes del sabio Colocolo, del intrépido Caupolicán, del imperturbable Rencií reviven el germen precioso, que no pudieron extinguir tres siglos de devastación y tiranía...»44

Otro tema habitual a lo largo de 1813 fue el de la condena a la tiranía española en oposición a la justicia de la causa americana. Así planteado aparecía en un artículo firmado por un desconocido que se autodefinía como un sarraceno

\footnotetext{
${ }^{38} \mathrm{CHICH}$, tomo 24, Semanario republicano: busca impulsar la independencia, p. 278.

${ }^{39} \mathrm{CHICH}$, tomo 24, Semanario republicano: busca impulsar la independencia, p. 281 .

$40 \mathrm{CHICH}$, tomo 26, El Monitor Araucano, 8 de abril de 1813, p. 8.

${ }^{41} \mathrm{CHICH}$, tomo 26, El Monitor Araucano, 13 de abril de 1813, p. 22.

${ }^{42} \mathrm{CHICH}$, tomo 26, El Monitor Araucano, 15 de abril de 1813, p. 31.

${ }^{43} \mathrm{CHICH}$, tomo 26, El Monitor Araucano, 11 de mayo de 1813, p. 113.

${ }^{44}$ Aurora de Chile, № 6, jueves 20 de agosto de 1813 .
} 
(denominación de los contrarios al cambio de sistema político), aunque arrepentido luego de haber visto la creación del Instituto Nacional; la reunión de los pueblos de indios «para mejorar a estos hombres ultrajados por tres siglos»; el fomento de la población, la educación, la artesanía y los recursos del reino. «He visto dotadas todas las instituciones sin gravar el erario... y veo que los tales pueblos de indios seguramente dan para su felicidad... Sarracenismo entremos en juicio... chileno me hice, y chileno soy...» ${ }^{45}$ Otro artículo editorial estuvo destinado a mostrar

«los crímenes de España... manchada por gran7des delitos contra el género humano... Favorecida con vastas, nuevas y opulentísimas regiones, en vez de civilizarlas no hizo más que destruirlas tratando como a brutos a sus antiguos habitantes. Su sangre clama al cielo...»46

Continúa el mismo tema en el número siguiente pero analizándolo contemporáneamente:

«Las violentas medidas de bárbara ferocidad adoptadas contra las Américas por los nuevos gobiernos españoles, prueban bien que el espíritu de opresión y tiranía es común a toda aquella nación, y que sus delitos son nacionales». ${ }^{47}$

La misma línea contraria a España e identificadora con los araucanos, se desarrolló en el periódico La Ilustración Araucana, ${ }^{48}$ de 1813 del que se publicaron sólo dos ejemplares, redactado por el portugués Antonio Gómez de Castro y el presbítero Juan José Uribe. En el primer número se hablaba de Chile como la nación araucana gobernada por un congreso nacional, a la que han venido a esclavizar los europeos. Ante esta situación, era necesario que revivieran Lautaro, Caupolicán y Colocolo porque sólo el cambio de sistema político podía garantizar la introducción de los principios liberales, sostenidos por el desarrollo de la agricultura, el comercio y la industria.

Ese mismo año se tomaron un conjunto de medidas gubernamentales tendientes a la integración de los indios al nuevo sistema político. El 25 de junio se dictaba un decreto sobre la reunión de los pueblos de indios para emprender con sus fondos la creación del Instituto de Artes y Oficios. ${ }^{49}$ En julio de 1813,

${ }^{45} \mathrm{CHICH}$, tomo 27, El Monitor Araucano, pp. 7 y 8.

${ }^{46} \mathrm{CHICH}$, tomo 27, El Monitor Araucano, p. 76.

${ }^{47} \mathrm{CHICH}$, tomo 27, El Monitor Araucano, martes 14 de septiembre de 1813, p. 79.

48 Guillermo Feliu Cruz, Biblioteca Nacional, Colección de Antiguos Periódicos Chilenos, Santiago, Ediciones de la Biblioteca Nacional, Viva El Rey. Gazeta Del Gobierno De Chile. Ilustración Araucana, Sacada De Los Arcanos De La Razón. El Augurio Feliz. 1813-1817, Santiago, 1952, 349352.

${ }^{49}$ Colección de Historiadores y Documentos... 75.

Hispania Sacra, LXIII

128, julio-diciembre 2011, 627-652, ISSN: 0018-215-X 
la Junta de Gobierno con acuerdo del Senado, dictó un Reglamento a favor de los indios, ${ }^{50}$ en el que afirma conocer la miseria, incivilidad, falta de moral y de educación en la que viven en los pueblos de indios. Por ello, y «deseando hacer efectivos los ardientes conatos con que proclama fraternidad e igualdad» decretaba que los pueblos de indios se transformaran en villas, unas dos o tres, en las que residirían los que fueran indios y gozarían de los derechos de ciudadanía correspondientes a los chilenos. En las villas podían residir españoles y miembros de otras clases con el fin de terminar con las diferencias de castas.

Según el decreto, las villas contarían con una iglesia, con su cura; una casa consistorial; una cárcel; escuela de primeras letras en las que se enseñaría a leer y escribir y la doctrina cristiana. Cada familia indígena recibiría una casa y una propiedad rural que podría disponer con absoluto y libre dominio. Por una sola vez se le iban a entregar a los indios una yunta de bueyes, semillas, arado y un telar. Todo se financiaría con las erogaciones de los mismos pueblos que se pondrían en remate, lo que se anunciaría públicamente para desarrollar el interés por el mismo. Como bien señala Fernando Silva Vargas, lo novedoso de este decreto era que se variaba el régimen de tenencia de la tierra, desaparecían las tierras de comunidad y el indio quedaba en libertad de enajenar sus tierras. ${ }^{51} \mathrm{De}$ esta manera, se abolían las repúblicas de indos y españoles creadas artificialmente por las Leyes de Indias.

Este decreto de 1813 representaba en algunos aspectos una continuación con la política iniciada por la Monarquía en el siglo XVII relativa a la modificación del régimen laboral de los indios que tendía a la sustitución de la encomienda por el trabajo asalariado. Dado que los indios vivían en las estancias de los encomenderos, sus pueblos se habían despoblado, ${ }^{52}$ proceso que favoreció la entrega de las tierras de esos pueblos en merced a los españoles.

A mediados del siglo XVIII la política de fundación de villas llevada a cabo por el gobernador Manso de Velasco acentuó el proceso, ya que muchas de ellas se fundaron en tierras de pueblos de indios ${ }^{53}$ Los gobernadores Benavides y O'Higgins, a partir de 1782, pusieron en práctica una política de reunión de pueblos de indios que facilitó la enajenación de sus tierras. ${ }^{54}$ Según Barros Arana, a principios del siglo XIX eran pocos los pueblos de indios que aún quedaban y pervivieron aún unos cuarenta años después de estas medidas. ${ }^{55}$

\footnotetext{
50 Sesiones de los Cuerpos Legislativos 1811 a 1845, tomo 1, p. 285.

${ }^{51}$ Fernando Silva VARgas, «Tierras y pueblos de indios en el reino de Chile. Esquema histórico-jurídico», Estudios de Historia del Derecho chileno, 7, Facultad de Ciencias Jurídicas, Políticas y Sociales, Pontificia Universidad católica de Chile, 200.

52 Ibidem 118.

53 Ibidem 152.

54 Ibidem 157 y sig.

${ }^{55}$ Diego Barros Arana, Historia General de Chile, tomo 9, Rafael Jover, (editor), 1888, 218.
} 
¿Cómo podemos entender la posición de los patriotas ante los indios? Para José Bengoa, a partir de 1810 los criollos incorporaron ideológicamente la cuestión indígena en el discurso anticolonial, idealizando el Arauco indómito por la necesidad de articular un discurso emancipador. ${ }^{56}$ Sin negar esta interpretación, creemos que también hay que considerar que los criollos tenían elementos propios para el fin que señala Bengoa, como la acusación de la infancia política a la que habían estado sometidos por la Monarquía, los reclamos criollos de los siglos anteriores como el de la limitada salida profesional y de obtención de cargos políticos, la tiranía del monopolio comercial, el sentimiento de los americanos de ser tratados como colonias, etc.

Por eso nos parece necesario complementar la interpretación de Bengoa en el sentido de tener en cuenta de que el recurso al mito de Arauco no apuntaba solamente a obtener contenidos ideológicos, sino que los patriotas más radicales tenían ya el objetivo de incorporar a los indios al nuevo sistema político considerándolos iguales a todos los habitantes, lo que en el entendimiento de la época significaba el fin de la sociedad de castas y de la república de los indios. Por lo que creemos que la idealización de Arauco tenía un doble mensaje, hacia los araucanos implicaba una incorporación de ellos mismos y su historia a un nuevo Chile, y hacia los criollos apuntaba a la independencia y el establecimiento de una nueva sociedad, libre e igualitaria, como quedó plasmada en el escudo patrio.

\section{LA RUPTURA ENTRE LOS PATRIOTAS Y LOS ARAUCANOS}

Como hemos dicho en diferentes partes del texto, a partir de marzo de 1813 arribaron a Chile tres expediciones españolas enviadas por el virrey del Perú, Fernando de Abascal, para reconquistar el territorio que se consideraba en situación de independizarse. La primera de ellas, mandada por el brigadier Antonio Pareja, según Tomás Guevara, no modificó la neutralidad de los araucanos ${ }^{57}$ pero marcó el inicio del cambio a raíz de la propaganda antipatriota llevada a cabo entre ellos por los franciscanos españoles del Colegio de Propaganda Fide de Chillán y el obispo de Concepción, Diego Antonio Navarro Martín de Villodres.

Los enfrentamientos armados entre patriotas y realistas no dieron a ninguno la victoria total, pero las fuerzas realistas pusieron un enclave propio en la ciudad de Chillán, donde lograron atrincherarse. Según Tomás Guevara, fue este el

56 José BengoA, Historia del pueblo mapuche, siglo XIX y XX, Santiago, LOM Ediciones, 2000, 143.

57 Cfr. Tomás Guevara, 5.

Hispania Sacra, LXIII

128, julio-diciembre 2011, 627-652, ISSN: 0018-215-X 
momento en que los realistas concibieron la idea de recuperar el control de la frontera araucana. La tarea fue dirigida por el comandante Juan Francisco Sánchez apoyado por los franciscanos del Colegio de Propaganda Fide. Teniendo como base de operaciones la ciudad de Chillán, los realistas lograron controlar los fuertes de la alta y baja frontera y, desde allí, los misioneros emprendieron una eficaz prédica entre los indígenas a favor de la causa del rey. Los indios engrosaron entonces las fuerzas realistas bajo la promesa de que se les mantendría su libertad e independencia.

Estas circunstancias tuvieron eco en la prensa patriota. A partir de agosto de 1813 no hubo más expresiones de identificación en El Monitor entre patriotas y araucanos, lo que muestra que estos últimos ya colaboraban con los españoles. Por otro lado, desde julio, las referencias a los indígenas en el periódico se refieren a aquellos que habitaban al norte del río Bío-Bío. Todo anunciaba los acontecimientos siguientes.

En efecto, con la llegada de la segunda expedición militar, mandada desde el Perú, se sellaba la alianza entre araucanos y españoles. El general Gabino Gaínza, al mando de la misma, convocó un parlamento en febrero de 1814 en el fuerte de Arauco, en el cual se confirmaron todos los acuerdos previos entre españoles e indígenas. Los caciques concurrentes recibieron aguardiente, y dos obsequios que les mandaba el virrey del Perú, un bastón de mando y una medalla con la efigie de Fernando VII. 58

Pero esta segunda expedición, como la primera, llegó a un punto muerto en lo militar para ambas partes. Gaínza no logró tomar Santiago y Bernardo O'Higgins, al frente de las tropas patriotas tampoco pudo derrotarlo. Ambos jefes firmaron el Tratado de Lircay por el cual las tropas realistas se comprometían a abandonar el territorio chileno mientras que Chile debía reconocer al Consejo de Regencia y jurar la constitución de Cádiz. Ni el virrey ni la Junta en Santiago ratificaron el tratado. La llegada de una tercera expedición desde Lima al mando del general Mariano Osorio selló el destino de Chile. Los patriotas fueron derrotados en la batalla de Rancagua (1 y 2 de octubre de 1814), Osorio avanzó hacia Santiago y se restableció la Monarquía mientras el grueso de los patriotas emigraba hacia Mendoza.

Para el año 1816 ya se sabía en Chile que se estaba afinando el gran ejército que en Mendoza estaba formando el general José de San Martín, gobernador intendente de Cuyo. Mientras San Martín sellaba una alianza con los pehuenches para que les permitieran cruzar la cordillera por su territorio y facilitaran los contactos con Chile, en Concepción el intendente celebraba un nuevo parlamento con los mapuches que reiteraban su adhesión a Fernando VII. ${ }^{59}$

\footnotetext{
${ }^{58}$ Historia General de Chile... 322-323.

59 Tomás GuevarA, 249-252.
} 
LA GUERRA A MUERTE

La victoria del Ejército de los Andes en las batallas de Chacabuco (12 de febrero de 1817) y Maipú (5 de abril de 1818), dispersó a las fuerzas realistas de la zona central de Chile. Una buena parte de ellas huyeron hacia el sur desplazándose el escenario de la guerra en la que entraron de lleno los araucanos apoyando a los españoles. Comenzó entonces la peor etapa de los enfrentamientos, la guerra a muerte ${ }^{60}$ entre los patriotas y las guerrillas españolea lideradas por Vicente Benavides, quien contaba con el apoyo de los hermanos Pincheira, banda de salteadores, y de los pehuenches, mapuches que habitaban en la cordillera.

La situación comenzó a cambiar recién a fines de 1819, cuando una victoria militar del general Ramón Freire sobre Benavides inició el control patriota del sur. Benavides fue por fin vencido en 1821 y murió en la horca en Santiago al año siguiente. Pero la guerra continuó adquiriendo en muchos casos las características del pillaje en una zona de frontera fundamentalmente por las acciones emprendidas por los Pincheira. ${ }^{61}$ Todo esto condujo a que paulatinamente los indios fueran cambiando de posición política.

\section{LOS INDIOS EN LA REPUBLICA CHILENA}

Durante el gobierno de Bernardo O'Higgins como Director Supremo, el 12 de febrero de 1818 Chile declaraba su independencia y se procedía a elaborar una constitución, que establecía un Senado Conservador de las Leyes y la Constitución, órgano consultivo del Director Supremo. Con respecto a los indios, el Senado les exigió la defensa de la patria ${ }^{62}$ por haber salido ya del «estado abyecto de tributarios o esclavos... y tienen voz y voto como ciudadanos libres». ${ }^{63}$ Como tales, eran iguales a todos ante la ley, porque la constitución los había sacado «del humilde pupilaje en que los tenía el gobierno español». ${ }^{64}$

Por eso debían entregar las tierras que poseían precariamente en los pueblos de indios para que se hiciera un nuevo reparto de tierras. Para ello el Senado encargó al Protector de Naturales que arbitrara en el proceso quien, además, les garantizaba defenderse por sí y no vivir sujetos a los caciques. En sesión del 21

\footnotetext{
60 Ver Benjamín VICUÑA MACKENNA, La guerra a muerte, memoria sobre las últimas batallas de la independencia de Chile, 1819-1824, Santiago, Imprenta Nacional, 1868.

61 Sesiones de los Cuerpos Legislativos...tomo 8, 367.

62 Ibidem, tomo 2, Santiago, Imprenta Cervantes, 1886, 302.

63 Ibidem 309.

64 Ibidem 496.
} 
de mayo de 1819, se acordaba mantener a los indígenas en posesión de los terrenos que ocupaban mientras el gobierno procedía al repartimiento. ${ }^{65}$

Un decreto del 3 de junio de 1818 firmado por el Director Supremo Bernardo O'Higgins establecía que al ser Chile un estado independiente de España debía terminarse con la denominación de español y pasar a la de chileno. En todos los documentos civiles y judiciales debía sustituirse el español natural de por el de chileno natural de, incluyendo a los indios. ${ }^{66}$

La constitución de 1818 no emanó de un órgano representativo. Los opositores a O'Higgins lo acusaban de concentrar en sí mismo todo el poder, exigieron una nueva constitución. En 1822 el gobierno convocó para ese fin una Convención Preparatoria que acordó como una de sus tareas la paz y civilización de los indios. ${ }^{67}$ Fue el cabildo de la ciudad de Chillán el que puso nuevamente el tema de los pueblos de indios, al pedir a la Convención que se vendiera a favor del estado el de Guambalí, repartiéndole tierra a los pocos indios que lo conformaban y el resto poniéndolo a la venta para que lo compraran los vecinos. ${ }^{68}$

También en octubre de 1822, la convención recibió una petición en el sentido de que las ganancias obtenidas de las ventas de los terrenos de los pueblos de indios, se aplicaran a aliviar la complicada situación de los habitantes de Concepción. En este contexto se sostuvo que los pueblos de indios eran refugio de malhechores que «defraudaban de sus derechos a los restos de los pocos que conservaban solo la memoria de sus primeros dueños y que hoy se hallan justamente declarados iguales y confundidos con los demás».69 Asimismo, Francisco Vargas, quien firmaba la representación del pueblo de Melipilla, sostenía que allí había cuatro espacios de ese tipo en los que trabajaban algunos perezosos residentes, faltando a otros la tierra más no la voluntad de trabajar.

Por su parte, el diputado por San Carlos ante la Convención, elevaba a ella varias peticiones del cabildo de su ciudad. Nos interesa la relativa a la reunión de los indios en un solo pueblo de los cuatro que había, con el fin de que el beneficio de los pueblos desocupados quedara para el partido. Los objetivos de esta propuesta eran tener «a la vista» a los indios, que se supieran sus actividades y cuidar la educación de sus hijos, de la que no se ocupaban. ${ }^{70}$ San Carlos también experimentaba la dificultad que implicaba la cercanía con uno de los,

\footnotetext{
65 Ibidem 488.

66 Archivo Nacional, Archivo de don Bernardo O'Higgins, tomo 11, Santiago de Chile, Imprenta Universitaria, Valenzuela, Basterriga y Cía., 1953, 81.

67 Sesiones de los Cuerpos Legislativos...tomo 6, 280, 335.

68 Ibidem. 284.

69 Ibidem 298.

70 Ibidem 322.
} 
así llamados, boquetes cordilleranos que permitían el contacto entre ambas bandas de la cordillera y que conectaba a los bandidos con los indios «bárbaros», en el comercio ilegal del ganado. Solicitaban el establecimiento de una guarnición militar permanente que acabara con los contactos por dicho boquete. ${ }^{71}$

Otras medidas que se tomaron fue la venta por parte del Estado de las tierras de indios para reequipar la escuadra nacional. ${ }^{72}$ Avanzado en la línea de convertir a los indios en asalariados, la comisión de industria de la Convención aprobó de la solicitud de Thomas Appleby para instalar una fábrica de sombreros, con la condición de que la mitad de los operarios fueran indígenas. ${ }^{73}$ En la sesión del 22 de septiembre de 1822 se destinaban los fondos de la venta de los pueblos de indios, según la ley del 1 de julio de 1813 , y de otros bienes secuestrados, a la instrucción científica e industrial del Estado. ${ }^{74}$

Finalmente la Convención aprobó una constitución a fines de 1822 que reconocía como una de las facultades del Congreso que establecía la de «cuidar de la civilización de los indios del territorio». ${ }^{75}$ Esta constitución no emanó de una discusión entre los diputados de las ciudades que la componían, sino que había sido escrita por uno de los hombres de confianza de O'Higgins, el ministro de hacienda Rodríguez Aldea. Creaba un ejecutivo fuerte, reelegible, lo que sumado a la intención del Director Supremo de perpetuarse en el poder, puso en marcha un movimiento opositor desde la sureña ciudad de Concepción.

En 1823 un nuevo congreso constituyente nombró como Director Supremo al general Ramón Freire, quien había encabezado la oposición a O'Higgins, y gobernó con un nuevo Senado Conservador. Este último acordó que los intendentes de provincia nombraran una comisión compuesta por un vecino y un agrimensor para poner a los indios en posesión de las tierras que ocupaban y las restantes, pertenecientes al Estado, se remataran. ${ }^{76}$ Las tierras que poseyeran los indios, se declaraban de propiedad perpetua. ${ }^{77}$ Aunque se inició el remate, este fue suspendido en 1832 a raíz de una solicitud de los indios de Llopeo. ${ }^{78}$

En un mensaje ante el Congreso, Freire sostuvo que, como había finalizado la guerra con los bandidos, llegaba el momento de reconstruir la línea de la frontera sur: «La gran mira del gobierno de Chile debe ser la civilización de

${ }^{71}$ Ibidem 323.

72 Ibidem 352.

${ }^{73}$ Ibidem 154.

${ }^{74}$ Ibidem, tomo 8, 223.

${ }^{75}$ Constitución política del Estado de Chile, 1822, cap. 6.

${ }^{76}$ Ricardo Anguita, Leyes promulgadas en Chile desde 1810 hasta el $1^{\circ}$ de junio de 1912, Santiago de Chile, Imprenta, Litografía y Encuadernación Barcelona, 1912, 119.

77 Valentín Letelier (comp.), Sesiones, tomo 7, p. 123.

${ }^{78}$ Fernando Silva VARGaS, op. cit. 203. 
los indios y su reunión a los demás chilenos, en términos que se forme una sola nación». A propuesta del Director Supremo, se discutió la posibilidad de establecer entre ellos colonias de extranjeros y traer familias inmigrantes, ${ }^{79}$ que también ayudaran al desarrollo industrial. ${ }^{80}$ Fueron solicitados informes a los gobernadores sobre los pueblos de indios vacantes en sus distritos y el valor de cada terreno en octubre de $1823 .{ }^{81}$

El Congreso también aprobó una ley que destinaba los fondos recaudados de la venta de los pueblos de indios vacantes a la instrucción de los hijos de los indios de esos mismos pueblos, en especial en artes o ciencias. ${ }^{82} \mathrm{~A}$ través de esto, recibirían «civilidad, moralidad, comodidad e instrucción para toda su descendencia».83

En 1824 el gobierno procedió a secuestrar las propiedades de los regulares que integraron, junto con los pueblos de indios, los bienes nacionales que serían vendidos a favor del erario público. En 1827 el diputado Francisco Meneses, presbítero, proponía al congreso la devolución de los bienes secuestrados a los regulares ${ }^{84} \mathrm{y}$, para resolver los apuros del erario, que fueran vendidos los pueblos de indios de Pomaire, Bajo Melipilla, Llopeo, Talagante y Gallardo ${ }^{85}$ medida ya decidida con anterioridad. Apoyada por la comisión de hacienda del congreso, propuso dividir el terreno en pequeñas hijuelas, que se subastaran a censo y no al contado con el fin de aumentar el número de propietarios de la nación. ${ }^{86}$

Pero también había llegado el momento de resolver la cuestión indígena en el territorio que se consideraba pacificado, como lo expresó el Director Supremo Ramón Freire, en su discurso ante el congreso constituyente del 12 de agosto de 1823. Para ello se dispuso que hubiera en las misiones religiosos capaces de responder al gran interés de la Patria: «reducir a vida social a los indios vecinos que manifiestan felices disposiciones». Pero también había que resolver la relación con los araucanos al sur de la frontera del Bío-Bío, «Los araucanos, nuestros padres, han recordado las glorias del antiguo Arauco», luego de haber sido seducidos por una conducta que enfrentaba a los hermanos «haciéndose agentes de la tiranía española». ${ }^{87}$

\footnotetext{
79 Sesiones de los Cuerpos Legislativos...tomo 7, 272.

${ }^{80}$ Ibidem 273, anexo 453.

81 Ibidem, tomo 8, 331 .

82 Ibidem 515.

83 Ibidem 317.

${ }^{84}$ Ibidem 192.

85 Ibidem, tomo $12,190$.

86 Ibidem 355 y 356.

87 Ibidem, tomo 8, 21.
} 
Se habían desengañado de ese error y estaban dispuestos a celebrar un parlamento luego de jurar paz eterna a sus hermanos, ser los primeros aliados de la nación y restituir las familias cautivas (unas 3.000 chilenas y 2.500 de Buenos Aires). Leyes posteriores afinaron estos puntos, como una, que proponía al gobierno de Buenos Aires el prorratear en común los gastos que ocasionaba la restitución de las familias. ${ }^{88}$

Asimismo, el congreso autorizaba al ejecutivo a celebrar un parlamento con los indios y que se incluyera el tema de la repoblación de las ciudades de Imperial, Angol y Villarica, ${ }^{89}$ todas al sur del río Bío-Bío. Otra ley de agosto de 1823 autorizaba al gobierno a demarcar la frontera sur siguiendo el curso del río Imperial, entregando terrenos a indios que quisieran reducirse a la vida social, reservando zonas para el establecimiento de colonias de inmigrantes extranjeros. ${ }^{90}$ Como bajo el dominio español, seguía considerándose una tarea del estado la conversión de los indios, para ello el senado conservador acordó en 1824 que nombraría un Comisario General de Cruzada previa presentación del director supremo, y el producto de la bula se destinaría a la conversión de los infieles y a la pacificación de la frontera..$^{91}$

Pero los hechos demostraron que la paz con los araucanos no era duradera y la piedra de tope era Chiloé. El senado recibía un informe en febrero de 1824 del gobernador intendente de Concepción en el que éste afirmaba que mientras Chiloé estuviera en manos de los enemigos no iba a ser posible pacificar a los araucanos ni acabar con los corsarios en el Pacífico sur.92 Por eso acordaron la autorización de la ocupación del archipiélago de Chiloé para aplacar el ánimo de los indios y que el Director Supremo estuviera al frente de la expedición ${ }^{93}$ y que se adoptaran las medidas necesarias contra las hostilidades de los «bárbaros araucanos».

La paz llegó de a poco. En 1824 se celebraron capitulaciones con el cacique Mariluán, ${ }^{94}$ por las cuales se suspendieron las hostilidades y el cacique aceptó la autoridad del gobierno. En 1825, en el parlamento de Tapihue, los mapuches reconocieron al gobierno republicano chileno. Paulatinamente, los españoles fueron retrocediendo y el general Freire los venció definitivamente recién en 1826.

Sin embargo, el gobierno tuvo que enfrentar en la provincia del Maule el ataque de los bandidos que reducían a la esclavitud a la población y la vendían

\footnotetext{
88 Ibidem 188, 194.

89 Ibidem 213.

90 Ibidem 74.

${ }^{91}$ Ibidem, tomo 9, p. 203.

92 Ibidem 80.

93 Ibidem 81.

94 Ibidem tomo $11,90$.
} 
a los indios salvajes. Para remediarlo, se dispuso para el mes de octubre de 1826 el envío de una expedición a las tierras de los indios pehuenches para exterminarlos. El principal objetivo de la expedición era el de entablar relaciones amistosas con los naturales, ser sus protectores, hacerlos cambiar de sus tradicionales actividades comerciales y lograr que ellos persiguieran a los bandi$\operatorname{dos}^{95}$ que vivían en sus territorios. Para ello era necesario que los pehuenches, mayoritariamente amigos de la república chilena, entendieran el mal que les causaban los bandidos que vivían entre ellos. ${ }^{96}$

El Congreso decidía que era necesario reedificar las ciudades de la frontera sur de Chile como único medio para poner término a la guerra con los indios «bárbaros», por lo que en 1826 ordenó la reedificación de la ciudad de Los Ángeles ${ }^{97}$ Asimismo, vio como prioritaria la reactivación del comercio previo a la guerra que la población del sur tenía con los naturales de los llanos, de la costa y de los montes de los Andes. Para que ello ocurriera proponían la celebración de un parlamento sobre la base de una paz estable «a fin de que se trate con ellos la seguridad con que deben contar sus propiedades».

El congreso proponía que se les mostrara la firmeza de la independencia de Europa, común a toda América, y que ellos no podían admitir en su seno a los enemigos de la republica chilena, tanto como esta a los de los indios. Se referían específicamente a los Pincheira, pidiéndoles que los entregaran o permitieran al ejército chileno entrar a buscarlo a sus territorios. Con todo esto se volvería a la antigua amistad y a la repoblación de las fronteras. ${ }^{98}$ Finalmente, el presidente Francisco Antonio Pinto, en su discurso del 25 de febrero de 1828 ante el congreso nacional, sostenía que se había alcanzado «la paz y la más perfecta armonía con los inmortales araucanos y en la guerra contra los bandidos han cooperado eficazmente con auxilios oportunos»..$^{99}$

\section{EL MITO ARAUCANO EN LA REPÚBLICA}

Como hemos visto, ya en la Patria Vieja se produjo la identificación del chileno con el araucano, de los que los criollos se consideraron herederos. Como bien señala Simon Collier la prensa pos independentista expresó, de manera destacada, esta identificación. ${ }^{100} \mathrm{Si}$ bien había referencias explícitas en muchos

\footnotetext{
95 Ibidem, tomo 12, 152.

96 Ibidem 228.

97 Ibidem 158.

${ }^{98}$ Ibidem, tomo 13, p. 78.

99 Ibidem, tomo 15, p. 264.

100 Simon Collier, Ideas y política de la independencia chilena, 1808-1833, Santiago, Editorial Andrés Bello, 1976, 200.
} 
periódicos, algunos lo hicieron directamente en sus sugerentes títulos, como las Cartas Pehuenches (1819), redactadas por Juan Egaña; el Despertador Araucano (1823), redactado por Joaquín Campino; el Correo de Arauco (1824), del redactor francés José Dauxion Lavaise; La Década Araucana (1825) cuyo primer redactor fue Juan Francisco Zegers y después Dauxion Lavaisse; El Insurgente Araucano (1827), redactado por Martín Orjeda y José Ignacio Izquierdo; ${ }^{101}$ y El Araucano (1830), periódico oficial de la república de Chile, fundado por Manuel José Gandarillas, Ministro de la Suprema Corte de Justicia. Como vemos, la mayoría de estos periódicos es posterior a la independencia.

Pero cabe la pregunta: ¿en qué sentido los chilenos de aquella época se sintieron herederos? Una respuesta la da El Insurgente Araucano:

«El título de este periódico manifiesta que así como los Araucanos jamás han dejado de combatir por su libertad, e independencia, los Chilenos descendientes de éstos, que siguieron su ejemplo desde el año 810, harán lo posible por sostener sus goces, y libertades que a costa de 16 años de tantos sacrificios adquirieron».102

En el mismo sentido se usó en El corresponsal del Imparcial, cuando en 1820 la ciudad de Valdivia, fue tomada por la armada chilena, luego de haber sido la más poderosa base naval española en el Pacífico sur, y la ciudad de Concepción se hallaba empobrecida por la guerra:

« ¿Por qué no extendéis una mano bienhechora a los territorios de Concepción y Valdivia? ;Oh! Allí reposan las cenizas de los padres y de los antiguos amigos de la libertad. Allí está el gran pueblo que celebró paz con el rey católico como de igual a igual...jOh! Toda la América había doblado la rodilla y besaba la mano del opresor, y sólo el estandarte de Arauco hacía frente a las banderas de la casa de Austria...»103

La misma identificación aparece en las Cartas Pehuenches de 1819, una recopilación de un supuesto intercambio epistolar entre dos mapuches, Melillanca recién llegado a la capital que le escribe a Guanalcoa para satisfacer los deseos de éste de saber lo que estaba ocurriendo:

«La actual revolución de Chile tiene el objeto más justo y necesario que puede interesar un pueblo: es el mismo por el cual nuestra nación sostuvo más de doscientos años la guerra, su libertad e independencia de la tiranía española; y si nosotros sufrimos las

${ }^{101}$ Los datos de las fechas de los periódicos y sus redactores en Ramón BRICEÑo, Estadística bibliográfica de la literatura chilena, Santiago, Imprenta Chilena, 1862.

102 El insurgente araucano, 10 de febrero de 1827, 2.

103 Guillermo Feliu Cruz, Biblioteca Nacional, Colección de Antiguos Periódicos Chilenos, Santiago, Ediciones de la Biblioteca Nacional, 1953, El Corresponsal del Imparcial, 1823, pp. 65-66.

Hispania Sacra, LXIII

128, julio-diciembre 2011, 627-652, ISSN: 0018-215-X 
atrocidades de Reinoso, Mendoza, Sotomayor, Quiñones, Lazo, etc., ellos a su vez, han tolerado la de Marcó, Osorio, San Bruno, Maroto, etc...104

Este periódico, publicado en la peor etapa de la guerra a muerte, tenía también un carácter pedagógico, buscaba mostrar a los chilenos las ventajas de algunas costumbres araucanas, como el carácter incorruptible de los indios. Por ello, en la segunda carta de Melillanca a Guanalcoa en la que le explica el sistema de justicia, le advierte:

«Te prevengo que encontrarás en esta relación muchas experiencias e ideas enteramente desconocidas en nuestros butalmapus... pues no encuentro en nuestro idioma y en nuestras costumbres palabras con que acomodarlas a tu inteligencia», ${ }^{105}$

tales como litigantes, engaño a los jueces, burocracia. Decide explicárselas a través de un caso ilustrativo en el que los jueces no trabajaban, los gastos de los trámites dejaban en la ruina a las personas, los culpables quedaban sin castigo y las víctimas sin justicia. Con respecto a la justicia mapuche, Melillanca sostenía que no aprobaba

\begin{abstract}
«...el método expeditivo de la administración de justicia, ni las leyes de tu Admapu, tan pocas como mal obedecidas; la pena del tablonco es inhumana y destructiva; esas malocas en que cada familia se hace justicia a sí misma, son un desorden social y los derechos que se abroga el ofendido para atacar por sí mismo la seguridad personal, son una horrible imagen de nuestras antiguas instituciones feudales, y de nuestros duelos».
\end{abstract}

Sin embargo esta forma de resolver los pleitos los hacía poco frecuentes y no quedaba impune el malvado. Reaparecía también el tema de la condena a la conquista española y sus funestas consecuencias, como introducción a la exaltación de las culturas americanas

«...no han poseído mayor cultura ni han permitido alguna en nuestros países, procediendo a destruir, sin aprovecharse, las que encontraron en nuestros indígenas. Así es que en un solo día quemaron en México todas las bibliotecas de jeroglíficos... despreciaron su calendario perpetuo que en dos mil años sólo variaba diez minutos... ignoran su delicado arte del vaciado y sobre todo el de vitrificar las piedras... un famoso matemático francés jamás pudo desaguar la laguna de México... Los araucanos, superiores a otras naciones en la elocuencia, en el sistema político federativo, y en algunas observaciones astronómicas, lo han sido sobre todo en la hidráulica... el canal del Salto es

104 «Cartas Pehuenches, 1819», Guillermo Feliu Cruz, Biblioteca Nacional, Colección de Antiguos Periódicos Chilenos, Santiago, Imprenta Cultura, 1958, p. 4.

105 «Cartas Pehuenches, 1819», Guillermo Feliu CRUZ, Biblioteca Nacional, Colección de Antiguos Periódicos Chilenos, Santiago, Imprenta Cultura, 1958, p. 10. 
asombroso por la inteligencia y la maestría con que se han vencido las dificultades del terreno...»106

Después de la caída de O'Higgins, en 1823, se publicaron otros periódicos que dieron nuevos contenidos al mito de Arauco. Uno de ellos fue El Despertador Araucano, ${ }^{107}$ que dedicó sus únicos dos números a mostrar el camino para que se llevara a cabo la segunda existencia política de América, la que llevaría a la felicidad. Si la primera existencia había sido la revolución de la libertad, era necesario avanzar hacia la segunda por medio del estudio de la economía, el desarrollo del comercio, la libertad de imprenta, la reforma de la administración, las sociedades públicas según el ejemplo de las reformas de Bernardino Rivadavia en Buenos Aires.

Juan Egaña también fue el redactor de El observador de Chile, periódico que apareció entre el 16 y el 23 de julio de $1823,{ }^{108}$ en el que se describe a Chile como la «... cuna de la libertad; apelo a los fieros Araucanos». ${ }^{109}$ Una nota que publicaba los brindis de la celebración del 9 de julio, día de la independencia de las Provincias Unidas del Río de la Plata, aludía a las reformas del ministro Bernardino Rivadavia en Buenos Aires, de corte liberal:

«Loor eterno a los chilenos que instruidos en las grandes reformas adoptadas en las provincias argentinas, aspiran a plantarlas en el territorio araucano, y para mejora de su país protejan el comercio, las artes, la agricultura, y den siempre un asilo seguro a todos los hombres, cualquiera sea su opinión política, o profesión religiosa». ${ }^{110}$

Chile, el territorio araucano, también debía convertirse en la tierra de la libertad republicana. La lucha por la libertad ya no se concebía sólo contra la opresión española, sino que implicaba adquirir las libertades individuales. Esta reelaboración del mito araucano en un contexto republicano se expresó también en los contenidos y títulos de otros periódicos. La Década Araucana, por ejemplo, de 1825, comienza con una frase de Montesquieu sobre la democracia representativa, la importancia de fomentar y defender toda especie de instituciones liberales, la unidad nacional en la Constitución, en la legislación,

106 «Cartas Pehuenches, 1819», Guillermo Feliu Cruz, Biblioteca Nacional, Colección de Antiguos Periódicos Chilenos, Santiago, Imprenta Cultura, 1958, 19.

107 Guillermo Feliu Cruz, Biblioteca Nacional, Colección de Antiguos Periódicos Chilenos, Santiago, Ediciones de la Biblioteca Nacional, 1953, 127-140.

108 Ramón Briceño, Estadística bibliográfica de la literatura chilena, Santiago, Imprenta Chilena, 1862 , p. 211.

109 «El Observador de Chile, 1823», Guillermo Feliu CRuZ, Biblioteca Nacional, Colección de Antiguos Periódicos Chilenos, Santiago, Ediciones de la Biblioteca nacional, 1953, 217.

110 «El Observador de Chile, 1823», Guillermo Feliu CRUZ, Biblioteca Nacional, Colección de Antiguos Periódicos Chilenos, Santiago, Ediciones de la Biblioteca nacional, 1953, 219.

Hispania Sacra, LXIII

128, julio-diciembre 2011, 627-652, ISSN: 0018-215-X 
en la administración. En sus páginas se defiende la tolerancia religiosa, la inmigración.

En el Correo de Arauco de 1824, el término Arauco significaba Chile y se sugiere, por su nombre, que se trata de la publicación de las noticias extranjeras e internas, según consta en el prospecto, se autodefinía no ministerial pero no por ello antiministerial. Todos estos elementos marcaban una diferencia con otros periódicos, menos destinados a la difusión de noticias, y más abocados a la publicación de las sesiones de los congresos o a discusiones públicas emanadas de los temas que se discutían en los órganos de gobierno. Por su parte, $E l$ Insurgente Araucano, de 1827 de tendencia liberal federalista destacaba la necesidad de volver al espíritu revolucionario de 1810, de levantarse contra la tiranía, ante la lucha de las facciones políticas que envolvían a Chile en la discusión sobre una nueva constitución centralista o federalista.

\section{CONCLUSIONES}

Nos propusimos en este artículo analizar la cuestión indígena en Chile a partir de 1810. Creemos que el tema en este período no ha sido suficientemente estudiado y que requiere de nuevas investigaciones que lo aborden en toda la profundidad que la temática requiere, sobre todo desde la óptica indígena, tema al que nos hemos referido. El espacio disponible en un artículo nos ha permitido fundamentalmente plantear tres aspectos, que creemos interrelacionados en su proceso de construcción histórica en cuanto a la cuestión indígena.

El primero, la consideración del indio a partir de 1810 como ciudadano en una sociedad más igualitaria, en cuanto tendía a la abolición de la sociedad de castas y de la república de los indios. Este proceso, y este es el segundo aspecto que analizamos, se desarrolló en íntima relación con la política lanzada por el ala radical de los patriotas tendiente a la identificación de criollos con los mapuche-araucanos durante el desarrollo de la guerra desatada a partir de la promulgación del Reglamento Constitucional de 1812. Esta política se expresó fundamentalmente en las proclamas gubernamentales y en la prensa, buscando conquistar a los criollos para que se abanderaran bajo las ideas de independencia y libertad, elementos centrales del mito de Arauco, y a los araucanos bajo las de igualdad social, paz y alianza ante el enemigo común. Ideas que no sedujeron a los araucanos y que produjeron un efecto contrario al esperado, ya que estos renovaron su alianza tradicional con los españoles, dando paso a la guerra a muerte y a múltiples campañas republicanas para pacificar los territorios controlados por los españoles gracias a la alianza con los indios.

Por último, y en tercer lugar, vimos cómo una vez establecida la república a partir de 1818, continuaron las políticas tendientes a desarticular la república de 
los indios e incluirlos en la nueva sociedad como ciudadanos. Como la implantación de la república se produjo mientras se desarrollaban las guerras de independencia, siendo uno de los enemigos los araucanos de la frontera sur, se reelaboró una nueva interpretación del mito de Arauco, en clave republicana. Los chilenos y los araucanos ya no eran los mismos, como en 1813, sino que los chilenos descendían de los araucanos. La libertad conquistada en 1810 debía mantenerse y desarrollarse hacia el objetivo de alcanzar la felicidad, es decir el progreso, introduciendo reformas liberales sobre la base de la democracia representativa para el desarrollo del comercio, la industria, la agricultura. Hacia fines de la década de 1820 se había alcanzado la paz con los araucanos, aunque no de manera definitiva, y su territorio no había sido efectivamente incorporado al del Chile independiente. Sin embargo, lo que perduró fue el establecimiento de un nuevo mito patrio, el de Arauco, sobre el que se desarrolló el sentimiento nacional. 